\title{
Toxicity studies and body weights changes in Wistar rats following oral administration of methanol extract from indigenous ganoderma sp. in Nigeria
}

\begin{abstract}
The acute and sub acute toxicity studies of methanol extract of Ganoderma lucidum was evaluated in Wistar rats using standard methods. Various doses (200, 400800 and 3200mg/ $\mathrm{kg}$ ) of the extract were orally administered to Wistar rats over a period of 24 hours in acute toxicity studies, while selected doses of 200,400 and $800 \mathrm{mg} / \mathrm{kg}$ of the extract were orally administered daily, for 21 days to rats according to body weights. Results of findings in both studies showed no apparent clinical sign of toxicity, and no gross lesion was observed in the excised organs (lung, liver, kidney, spleen and heart) of the experimental rats. The experimental rats responded well through increases in body weights throughout the study period. These findings showed safety of the methanol extract of the wild Ganoderma spp. in wistar rats, implying a wide margin of safety following consumption for a long period of time, especially at doses of 200 and $400 \mathrm{mg} / \mathrm{kg}$. the rats were equally observed to reverse changes in their physiological values following a withdrawal period of two weeks. This implied the effective biotransformation and elimination of this natural product within a short time period.
\end{abstract}

Keywords: toxicity, dose, methanol extract, ganoderma lucidum, wistar rats
Volume I Issue 5 - 2017

\author{
Shamaki BU,' Sandabe UK,' Abdulrahaman \\ FI, ${ }^{2}$ Ogbe AO, ${ }^{3}$ Hassan ZI, ${ }^{4}$ Yusuf IL, ${ }^{5}$ Bitrus \\ W,' Zongoma $Y,{ }^{\prime}$ Isikhuemhen $\mathrm{OS}^{6}$ \\ 'Department of Veterinary Physiology, Pharmacology and \\ Biochemistry, University of Maiduguri, Nigeria \\ ${ }^{2}$ Department of Chemistry, University of Maiduguri, Nigeria \\ ${ }^{3}$ Department of Veterinary Medicine, University of Abuja, Nigeria \\ ${ }^{4}$ Department of Community Medicine, University of Jos Teaching \\ Hospital, Nigeria \\ ${ }^{5}$ Department of Veterinary Pharmacology and Toxicology, \\ University of Ahmadu Bello, Nigeria \\ ${ }^{6}$ Department of Natural Resources \& Environmental Design, \\ North Carolina A\&T State University, USA
}

Correspondence: Shamaki BU Department of Veterinary Pharmacology and Toxicology, University of Maiduguri, Nigeria, Tel+2348065524181 Email shamakibalausman@gmail.com

\section{Introduction}

Traditional medicine is in recent times gaining acceptance in the healthcare delivery systems of many countries, with the World Health Organization reporting that over $80 \%$ of the world's population still relies on herbal medicine as their primary source of healthcare, and with millions of Africans of all ages relying on herbal medicines for primary healthcare. ${ }^{1}$ Which underscores the importance of herbal medicine in healthcare delivery system. Despite these, little effort is being made to apply traditional medicine into Veterinary practice ${ }^{2}$ beyond its use by herdsmen. Although, traditional medicine can be a source of medication to widen the therapeutic arsenal against range of diseases, ${ }^{3,4}$ it is important to know that plants produce diverse array of chemical substances that may form the basis for their use in traditional medicine to treat variety of disease conditions, and can therefore, be an enormous potential source of raw material for new chemotherapeutic agents. ${ }^{5}$ However, these chemicals produced by plants can have other unwanted pharmacological effects on some tissues, haematological parameters and other indices of production. Among a range of plants that are currently being investigated for there medicinal properties is the mushroom, Ganoderma lucidum. The evaluation of toxic activities of this mushroom is important in order to consider safe preparations that can enable the definition of the intrinsic toxicity and the effects the acute and sub acute dose of the mushroom has on its consumers. ${ }^{6}$ Although, extracts of this mushroom is reported to possess a number of pharmacologically active phytochemicals and elements ${ }^{7}$ with evidence of a lot of medicinal properties, ${ }^{8-14}$ it was also reported to have unwanted toxicological effects on internal organs such as liver, kidneys, lungs, spleen and the heart. ${ }^{15}$ Preparations of this mushroom are used as tea or components of immune boosters $\left(\right.$ immunoboost ${ }^{\mathrm{R}}$ ) and as other antioxidant supplement. This study is therefore important, to evaluate the acute and sub acute toxic effects of extracts of this mushroom.

\section{Materials and methods}

\section{Collection and identification of the mushroom}

Fresh fruiting part of the wild mushroom (G. lucidum) was harvested from Lafia, Nassarawa State in North-central Nigeria during the month of August-September, 2011 (rainy season) and was transported to Maiduguri inside in a clean bag. The mushroom was identified and authenticated by an expert mycologist at the Department of Biological Sciences, University of Maiduguri, Nigeria. It was then air-dried in the laboratory and ground to a fine powder using clean mortar and pestle and stored in an air-tight glass jar at $4^{\circ} \mathrm{C}$ until required.

\section{Extraction of the wild G. lucidum}

The dried powder of Ganoderma was weighed using a metler balance (Toledo-PB 153, Switzerland), and $1.5 \mathrm{~kg}$ of the dried powder was placed in a thimble and was put in a Soxhlet extractor, and extracted exhaustively with 7.5 litres of absolute methanol, extract was evaporated within a period of $24 \mathrm{~h}$, using electric evaporator.

\section{Laboratory animals}

A total of one hundred and thirty (130) albino rats, three weeks old, of different sexes weighing between 100 and $140 \mathrm{~g}$ were used 
for the toxicity studies. The rats were kept in plastic cages with open top, sealed with wire gauze in the Veterinary Physiology laboratory of the Department of Veterinary Physiology, Pharmacology and Biochemistry. Animals were acclimatized to laboratory conditions for 2 weeks before commencement of the experiment. The rats were fed with commercially formulated pelletized broilers feed-Grower mash produced by Vital feeds Company Nigeria Ltd, Bukuru, Jos, Plateau State Nigeria. Clean drinking water was provided ad libitum.

\section{Determination of body and organ weight changes in rats}

Changes in the body weights of the experimental rats were monitored on weekly basis by weighing each rat daily using a compact scale weighing balance (FEJ-3000B, 3000g capacity, China). Similarly, tissue samples from the lungs, liver, heart, kidney and spleen were collected from sacrificed rats daily, and were weighed using electronic weighing balance (SFE 300, Citizens scale, Adams equipment company limited, China) to determine the organ-body weight relationship.

\section{Toxicity studies}

\section{Acute toxicity studies $\left(\mathrm{LD}_{50}\right)$}

Thirty rats of both sexes, weighing $112 \mathrm{~g}-140 \mathrm{~g}$ were used in this study. These rats were divided at random into six groups (A, B, C, D, $\mathrm{E}$ and $\mathrm{F}$ ) of 5 rats each. The rats were allowed to acclimatize for two weeks in clean cages under laboratory conditions. They were fed with commercially formulated pelletized feed (Vital feeds Plc, Bukuru, Jos, Plateau State. Nigeria) and clean water, ad libitum. Rats in group A, B, $\mathrm{C}, \mathrm{D}$ and $\mathrm{E}$ were treated with crude methanol extract of G. lucidum at $200,400,800,1,600$ and $3200 \mathrm{mg} / \mathrm{kg}$ body weights respectively. Rats in group F served as untreated control and were given distilled water. All treatments were given orally. The rats were monitored for clinical signs, behavioural changes and death over a period of 24 hours. The $\mathrm{LD}_{50}$ was determined using the Arithmetic methods of Kerber ${ }^{16}$ as modified by Aliu and Nwude. ${ }^{17}$

\section{Sub acute toxicity studies}

One hundred albino rats of weights between $112 \mathrm{~g}$ to $140 \mathrm{~g}$, and aged four weeks of both sexes were randomly allotted into four groups (A, B, C, D, ) with twenty five rats in each group. Methanol extract of the wild G. lucidum was administered orally at varying doses of 200,400 and $800 \mathrm{mg} / \mathrm{kg}$ to three (3) groups A, B and C. While group $\mathrm{D}$ was administered with distilled water for the period of three weeks, and the remaining 2 weeks were not treated to observe for reversal in all the treatment groups, each week for five weeks (day $7^{\text {th }}, 14^{\text {th }}, 21^{\text {st }}, 28^{\text {th }}$ and $35^{\text {th }}$ ). Five rats from each group were sacrificed every week by severing the jugular vein. ${ }^{18}$ Thereafter, $1.5 \mathrm{ml}$ of blood collected into bijour bottles from each rat. Collected blood from each rat was divided into two equal parts. One part was used to analyse for haematological parameters, while the other part was allowed to clot and the serum analysed for biochemical parameters.

\section{Results}

In acute toxicity studies, oral administration of varying doses $(200,400,600,1,600$ and $3200 \mathrm{mg} / \mathrm{kg})$ of methanol fraction of the wild Ganoderma lucidum extract in Wistar rats caused itching around the mouths area which caused rats to scratch their mouths with their fore limbs. The observed effect increased with increase in the dose of the extract. The signs were noticed 20 minutes after the administration of the extract. These were observed especially in the rats that were treated with 1600 and $3200 \mathrm{mg} / \mathrm{kg}$. These signs were mild in rats given lower doses of 200 and $800 \mathrm{mg} / \mathrm{kg}$. There was no mortality recorded in all the treated groups, and all the treated experimental rats survived. (Table 1) in sub acute studies, Wistar rats treated with the extract at doses of 200,400 and $800 \mathrm{mg} / \mathrm{kg}$, did not show any apparent sign of toxicity as that observed in the acute toxicity studies. However the experimental rats in all the groups were observed to feed and drink water ad libitum normally, especially with higher doses of 1600 and $3200 \mathrm{mg} / \mathrm{kg}$ respectively. These signs (increase in feeding a drinking) were observed between 7-21 days (weeks of treatment) which declined during the withdrawal period at 28-35 days (two weeks withdrawal period) (Table 2).

Table I Acute toxicity studies of methanol extract of wild G. lucidum in rats ( $\mathrm{n}-5)$

\begin{tabular}{|c|c|c|c|c|c|}
\hline Group & Dose (mg/kg) & Average body weight (g) & Volume of extract administered ( $\mathrm{ml})$ & Mortality & Survivability \\
\hline A & 200 & $138.7 \pm 1.1$ & 0.14 & 0 & 5 \\
\hline B & 400 & $139.7 \pm 2, \mid$ & 0.5 & 0 & 5 \\
\hline C & 800 & $113.6 \pm 2.4$ & 0.4 & 0 & 5 \\
\hline D & 1600 & $129.2 \pm 1.5$ & I & 0 & 5 \\
\hline E & 3200 & $138 \pm 3.1$ & 1.2 & 0 & 5 \\
\hline $\mathrm{F}$ & Control Distilled water (ml) & $132.4 \pm 0.8$ & 1.2 & 0 & 5 \\
\hline
\end{tabular}

LD50 $\geq 3200 \mathrm{mg} / \mathrm{kg}$

Table 2 Effect of sub acute administration of methanol extract of wild G. lucidum on body weight in rats

\begin{tabular}{|c|c|c|c|c|c|c|}
\hline \multirow[t]{2}{*}{ Dose of extract $(\mathrm{mg} / \mathrm{kg})$} & \multicolumn{6}{|c|}{ Weekly body weight changes (g) (Mean \pm SD) Day } \\
\hline & 0 & 7 & 14 & $21^{*}$ & 28 & 35 \\
\hline 200 & $129.2 \pm 9.5$ & $128.6 \pm 9.0 \mathrm{c}$ & $128.5 \pm 9.5 \mathrm{c}$ & $138.7 \pm 1.1 \mathrm{a}$ & $134.0 \pm 16.1 \mathrm{a}$ & $164.3 \pm 19.6 \mathrm{a}$ \\
\hline 400 & $103.4 \pm 14-9 a$ & $105.8 \pm 15.2 \mathrm{c}$ & $109.3 \pm 15.1 b$ & $119.8 \pm 15.6 \mathrm{~b}$ & $135.1 \pm 11.9 b$ & $145.2 \pm 12.1 \mathrm{a}$ \\
\hline 800 & $119.8 \pm 10.1 b$ & $|20.8 \pm| 1.8 \mathrm{c}$ & $126.0 \pm 1 \mid .9 \mathrm{a}$ & $139.5 \pm 10.7 \mathrm{a}$ & $138.1 \pm 17.0 \mathrm{~b}$ & $148.5 \pm \mid 7.1 \mathrm{a}$ \\
\hline Control (distilled water) (ml/kg) & $125.0 \pm 20.9$ & $123.8 \pm 20.5$ & $127.1 \pm 20.3$ & $133.5 \pm 7.5$ & $146.7 \pm 7.8$ & $149.9 \pm 20.7$ \\
\hline
\end{tabular}

*: Cessation of treatment.

Mean with different superscript letters differ significantly $(P<0.05)$. 


\section{Body weight changes}

Rats treated with the extract had significant $(\mathrm{p}<0.05)$ increase in body weight after 21 days of treatment (Table 2). There were no significant changes in weights of treated rats 2 weeks after the cessation of treatment. The body weights of the rats before treatment were $129 \pm 9.5,103.4 \pm 14.9,119.8 \pm 10.1$ and $125.0 \pm 20.9$ for groups $A$, B C and D respectively. By 21 days of treatment, the body weights of rats were $138.7 \pm 1.1,119.8 \pm 15.6,139.5 \pm 10.7$ and $133.5 \pm 7.5$ in groups A, B C and D respectively. The pattern of weight gain was not interfered with during the withdrawal of the extract.

\section{Statistical analysis}

Data obtained from sub-acute studies was analysed by one way analysis of variance (ANOVA) using Graphpad InStat ${ }^{19}$ statistical software package to analyse the degree of variance among groups, and "p" values less than, or equal to 0.05 (Turkeys test) was considered significant.

\section{Discussion}

The increasing demand for the inclusion of plants extracts and other herbal preparations in both human and animal health programmes necessitate the toxic actions of the plant extract to assess their inherent toxicity levels and the effect of acute overdose ${ }^{6}$ this is to safeguard the safety limits of their use in both animal and man. Acute toxicity studies of the methanol extract of G. lucidum showed no mortality in experimental Wistar rats at high dose of $3600 \mathrm{mg} / \mathrm{kg}$ when administered orally. Thus, suggesting that the mushroom has low acute toxicity and has wide margin of safety. This finding agree with that of Clark and Clark ${ }^{20}$ that said substances whose LD50 in rats fall below $50-100 \mathrm{mg} / \mathrm{kg}$ should be regarded as very toxic, and those with LD50 above $500 \mathrm{mg} / \mathrm{kg}$ but below $1000 \mathrm{mg} / \mathrm{kg}$ are classified as being moderately toxic, while substances whose LD50 in rats are above $1000 \mathrm{mg} / \mathrm{kg}$ are considered safe or of low toxicity. This indicated that the methanol fraction of G. lucidum extracts can be administered orally in rats with some degree of safety. Reports by Dennis ${ }^{21}$ suggested that absorption of substances orally administered is interfered with in the gastrointestinal tracts, therefore, limiting the absorption rates, hence absence of gross toxicity signs observed. However, Oluba et al. ${ }^{22}$ Reported non toxic effect of the intra peritoneal (i.p) administration of aqueous extract of G. lucidum in rats, thus, indicating both routes produce no toxic effect of extract of this mushroom in rats. In this study, there was no apparent clinical signs of toxicity observed in both acute and sub acute studies when the extract was orally administered, however, it was observed that feed and water consumption increase within the period of study, thus causing an increase in body weights of experimental rats. This may be due to increase in metabolism and anti oxidant effect of the extract as reported by Oluba et al. ${ }^{22-24}$ while other reports indicate decrease in weight. ${ }^{25}$

The significant $(\mathrm{P}<0.005)$ increase in body weights of rats observed in both the extracts treated rats and the control groups suggest that the extract has no effects on feed conversion rates in the experimental rats. However, this may be influenced by the presence of steroids and saponins ${ }^{9}$ and with the reports that saponins can be converted to aglycon sapogenin (a steroid or triterpene) ${ }^{26}$ which may probably acts centrally and have stimulatory effects on feeding centers in the brain of experimental rats. Body weight changes can occur through alteration in growth especially when they contain agents that modify secretion of growth hormone or somatostatin, or through alteration of hormonal status eg, agents that modify secretion of sex steroids and therefore alter maturational pattern or through changes in neurotransmitters that affect food consumption, such as agents that affect central seratoninergic or dopaminergic systems, reduced palatability of diets containing the experimental compound or through non specific systemic toxicity ${ }^{27}$ Hence the increase in feed and water intake observed in the rats, and subsequently, increase in body weights in the extracts treated group compared to control and pre-treatment. Weight gain was not reversed following withdrawal period of two weeks, thus, implying effective feed conversion in the experimental rats. Although there was no apparent gross lesion observed in both studies, the methanol extract was reported to cause histopathological changes in most of the studied organs reported by Oluba et al., ${ }^{18,28}$ and Shamaki et al. ${ }^{15}$ This implies that prolonged administration cum consumption of extract of Ganoderma lucidum at higher doses $(>400 \mathrm{mg} / \mathrm{kg})$ may show no apparent gross lesion, but can cause damages to some internal organs.

\section{Conclusion/recommendation}

It was therefore concluded that methanol extract of G. lucidum did not produce any gross lesion in rats and can be considered safe when administered orally, and recommended that such should be exploited in further research for medicinal purpose. Furthermore, feeding and drinking habits of rats under G. lucidum extract treatment should be carried out to evaluate its veracity and equally presence or otherwise, of possible anti-nutritive elements in the mushroom extracts.

\section{Acknowledgements}

We wish to acknowledge the technical assistance of technologists in the Physiology and Pharmacology Laboratory of the Department of Veterinary Physiology, Pharmacology and Biochemistry, Faculty of Veterinary Medicine. University of Maiduguri, Nigeria.

\section{Conflict of interest}

The author declares no conflict of interest.

\section{References}

1. McCaleb, A. McCaleb's traditional medicine added to national plan of action for Africa, ASNAPP UNDATA and A. France: SNSPP Newsletter publication; 2000. p. 25-29.

2. Geidam YA, Ambali AG, Onyeyili PA. Phytochemical screening and antibacterial properties of organic splvent fration Psidium guajava acqueous leave extract. International Journal of Pharmacology. 2007;3(1):68-73.

3. Jaramillo S. Nturismo comosistema sanitario social. Barcelona Leima. 1989. p. $1-100$.

4. Khan, Jan SA, Shinwari, Ali ZK, et al. Ethnobotany and medicinal Uuses of folklore medicinal plants belonging to family Acanthaceae: An updated review. MOJ Biology and Medicine. 2017;1(2):00009.

5. Adewunmi CO, Agbedahunsi JM, Adebayo AC, et al. Ethnoveterinary medicine screening of Nigerian plants for trypanocidal properties. Journal of Ethnopharmacol. 2001;77(1):19-24.

6. Caceras A. Textbook of plants use in Guatemala (Plantas de uso medicinal en Guatemala). 1st ed. Editorial Universitaria, Guatemala: San Carlos de Guatemala; 1996. p. 61-328.

7. Shamaki BU, El-Yuguda AD, Abdulrahman FI, et al. In vitro inhibition of neuraminidase activity of influenza virus (h5n2) by methanolic soluble fraction of ganoderma lucidum extract. International Journal of Modern Biology and Medicine. 2013;4(3):147-154. 
8. Shamaki BU, Geidam YA, Abdulrahman FI, et al. Evaluation of phytochemical constituents and in vitro antibacterial activity of organic solvent fraction of Ganoderma lucidum methanolic extract. Int J Med Plants Res. 2012;1(3):26-31.

9. Shamaki BU, Sandabe UK, Abdulrahman FI, et al. Proximate composition, phytochemical and elemental analysis of some organic solvent fraction of the wild mushroom, ganoderma lucidum. Journal Natural Science Research. 2012;2(4):24-35

10. Shamaki BU, Sandabe UK, Ogbe AO, et al. Methanolic soluble fraction of linghzi or reishi medicinal mushroom ganoderma lucidum (higher basidiomycetes) extract inhibit neuraminidase activity in newcsatle disease Virus (LaSota). Int J Med Mushrooms. 2014;16(6):579-583.

11. Shamaki BU, Ogbe AO, Abdulrahman FI, et al. Effects of prolonged administration of methanolic extract of ganoderma lucidum on blood glucose level in normal albino rats. International Journal of Pharmaceutical Research and Analysis. 2014;4(2):122-124.

12. Shamaki BU, Ogbe AO, Balla HJ, et al. Potential antiviral activities of $(\%)$ of three organic solvent fractios of wild Ganoderma lucidum (Higher Basidiomycetes) extract against infectious bursal disease (IBD). Journal of Pharmaceutical Biology. 2014;4(3):133-137.

13. Shamaki BU, Sandabe UK, Ogbe AO, et al. Methanolic soluble fraction of linghzi or reishi medicinal mushroom ganoderma lucidum (higher Basidiomycetes) extract inhibit neuraminidase activity in newcsatle disease virus (LaSota). International Journal of Medicinal Mushroom. 2014;16(6):579-583.

14. Shamaki BU, Sandabe UK, Abdulrahman FI, et al. Effect of sub acute administration of ganoderma lucidum methanolic extract on some biochemical parameters in wistar rats. European Journal of Biomedical and Pharmaceutical Research. 2015;2(1):364-375.

15. Shamaki BU, Sandabe UK, Gambo HI, et al. Histopathological finding following prolonged administration of crude methanol soluble fraction of ganoderma lucidum extract in albino rats. Sahel Journal of Veterinary Science. 2016;2(1):93-99.

16. Kerber G. Betrag zur kollectriven behandlung pharmacologischer reihenversuche. Archives of Experimental Pathology and Pharmacology. 1931;162:480-483.

17. Aliu YO, Nwude N. Veterinary pharmacology and toxicology experiments. Nigeria: Baraka press Nigeria Ltd; 1982. p. 104-109
18. CIO MS. Council for International Organization of Medicinal Session. International Guiding Principles for Biomedical Research Involving Animals. Geneva, Switzerland: WHO; 1985.

19. Graphpad InStat. Graphpad InStat statistical software, USA: 2003.

20. Clarke, ECG, Clarke ML. Toxicity levels of various compounds: In Veterinary Toxicology. 1st ed. UK: Bailliere Tindall; 1977. $10 \mathrm{p}$.

21. Dennis VP. Mammalian metabolism of xenobioticschemicals. In: Kacew, editors. New York USA: Toxicology and Newborn Academic publishing; 1984. p. 1-32.

22. Oluba OM, Onyeneke EC, Ojieh GC, et al. Hepatoprotective potential of aqueous extract of ganoderma lucidum against carbon tetrachloride intoxication in rats. Scholars Research Library, Der Pharmacie Lettre. 2010;2(2):432-439.

23. Rajasekaran M, Kalaimagal C. Cardioprotective effect of a medicinal mushroom, ganoderma lucidum against adriamycin induced toxicity. International Journal of Pharmacology. 2012;8(4):252-258.

24. Hossain S, Rhowmick S, Islam S, et al. Oral Administration of ganoderma lucidum to lead exposed rats protects erythrocytes against hemolysis: implicates to anti-anemia. (hindawi publishing corporation). Evid Based Complement Alternat Med. 2015;463703.

25. Donmez DB, Yilmaz G. Effect of ganoderma lucidum (red reishi mushroom) on the genital system in female rats. Merit Res J Med Sci. 2014;2(7):141-145.

26. Abdulrahman FI. Studies on the chemical contents and Pharmacological activities of the root-bark extract of Vitex doniana (Black plum). A PhD thesis submitted to the department of chemistry, faculty of science, University of Maiduguri, Borno State, Nigeria: 2004.

27. Bailey SA, Zidell RH, Perry RW. Relationship between organ weight and body/brain weight in the rta: what is the best analytical endpoint? Toxicol Pathol. 2004;32 (4):448-466.

28. Ogbe AO, Atawodi SE, Abdu PA, et al. Oral treatment of eimeria tenellainfected broiler using acqueous extract of wild mushroom (ganoderma sp.): effect on haematological parameters and histopathological lesions. African Journal of Biotechnology. 2010;9(52):9823-9827. 